\title{
Oriental Cockroach, Blatta orientalis Linnaeus (Insecta: Blattaria: Blattidae:) $)^{1}$
}

Kim McCanless ${ }^{2}$

\section{Introduction}

The origin of the oriental cockroach, Blatta orientalis Linnaeus, is uncertain, but it is thought to be from Africa or south Russia. It is a major household pest in parts of the northwest, mid-west, and southern United States. It is also sometimes referred to as the "black beetle" or a "water bug" because of its dark black appearance and tendency to harbor in damp locations.

\section{Description}

The oriental cockroach is approximately 1 inch long (22 to $27 \mathrm{~mm}$ ) and dark brown to black. Males have wings covering $3 / 4$ of their body, and the female has very short (rudimentary) wings. The inner wing folds like a fan and is membranous. The outer part of the wing is narrow, leathery and thick. The styli between a pair of jointed cerci can identify the male. Both the male and female are flightless.

\section{Life Cycle}

A female oriental cockroach produces an average of eight egg capsules per lifetime. Each egg capsule or ootheca contains about 16 eggs that are lined up

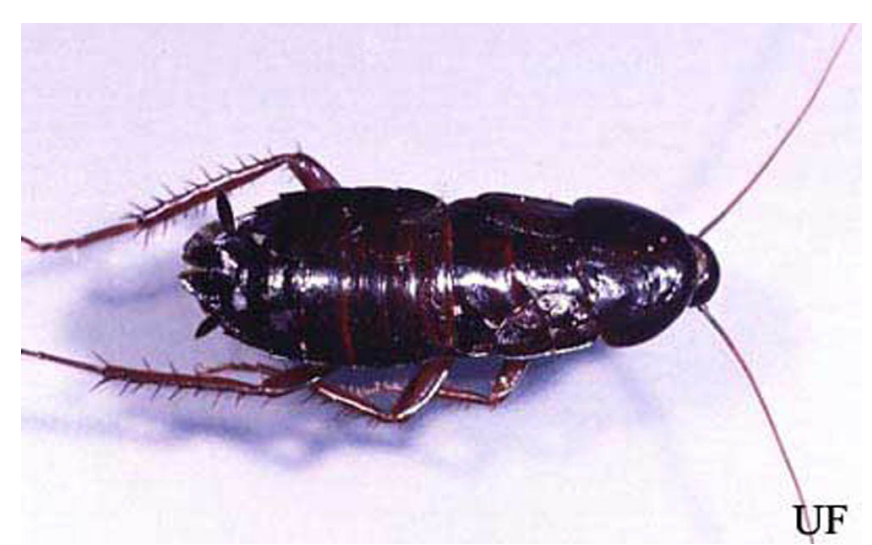

Figure 1. Female oriental cockroach, Blatta orientalis Linnaeus. Credits: Paul M. Choate, University of Florida

vertically, two by two in the egg case. The egg capsule may be carried from 12 hours to five days and then deposited in a warm sheltered environment where food is readily available. The incubation period for the oriental cockroach is a bout 42 to 81 days. The female gives no assistance to the young. Nymphs go through seven molts before becoming adults, which takes approximately one year. An adult B. orientalis can live from 34 to 180 days, and pairing takes place at any season.

1. This document is EENY-159, one of a series of Featured Creatures from the Entomology and Nematology Department, Florida Cooperative Extension Service, Institute of Food and Agricultural Sciences, University of Florida. Published: October 2000. This document is also available on Featured Creatures Website at http://creatures.ifas.ufl.edu. Please visit the EDIS Website at http://edis.ifas.ufl.edu. Additional information on these organisms, including many color photographs, is available at the Entomology and Nematology Department website at http://entnemdept.ifas.ufl.edu/.

2. Kim McCanless, Entomology and Nematology Department, University of Florida, Institute of Food and Agricultural Sciences, Gainesville, FL.

The Institute of Food and Agricultural Sciences is an equal opportunity/affirmative action employer authorized to provide research, educational information and other services only to individuals and institutions that function without regard to race, color, sex, age, handicap, or national origin. For information on obtaining other extension publications, contact your county Cooperative Extension Service office. Florida Cooperative Extension Service/Institute of Food and Agricultural Sciences/University of Florida/Christine Taylor Waddill, Dean. 


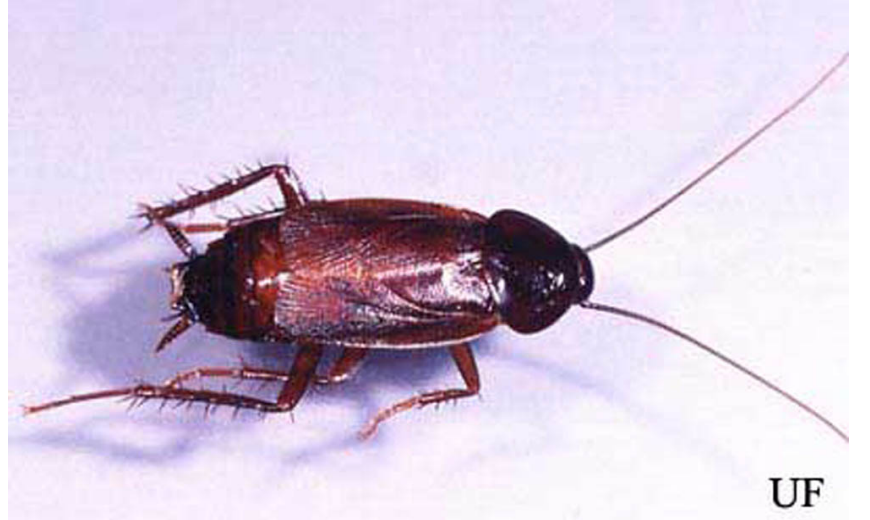

Figure 2. Male oriental cockroach, Blatta orientalis Linnaeus. Credits: Paul M. Choate, University of Florida

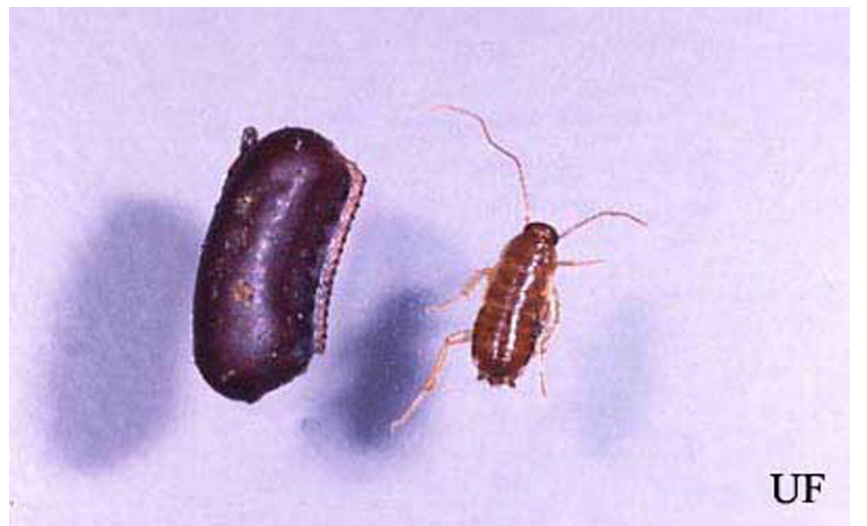

Figure 3. Egg case (ootheca) and early instar nymph of the oriental cockroach, Blatta orientalis Linnaeus. Credits: Paul M. Choate, University of Florida

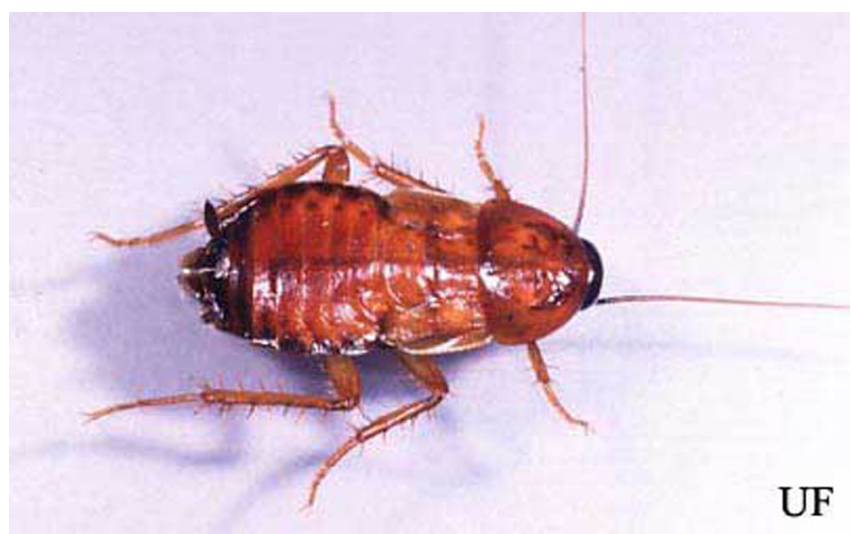

Figure 4. Late instar nymph of the oriental cockroach, Blatta orientalis Linnaeus. Credits: Paul M. Choate, University of Florida

\section{Detection}

Any area that has a high humidity and a cool temperature should be examined. Crawl spaces, basements, and kitchen and bathroom plumbing can be inspected for dead roaches, egg cases, and fecal smears. Also, any spider webs in these locations can be inspected for cockroach remains.

\section{Habits and Habitat}

Blatta orientalis is common outdoors, and lives in warm damp shady areas near the ground or any area containing natural debris. It will often seek refuge indoors when a drop in temperature occurs, but is still quite tolerable of cooler weather. The most common areas to find B. orientalis are basements, crawl spaces, areas between the soil and foundation, underneath sidewalks, in sewer pipes, in floor drains, and under sinks or any other damp cool area in the house. The roach travels through the structure on plumbing pipes. Outside the house they sometimes aggregate near or under garbage cans. The species tends to be seasonal, with adults appearing in spring and summer. When large numbers of roaches occur, overcrowding can lead to the mass migration of roach species such as the German cockroach, Blattella germanica, the American cockroach, Periplaneta americana, and the oriental cockroach.

\section{Diet}

The oriental cockroach is often found feeding on garbage, sewage, or decaying organic matter and will eat almost anything. A diet high in starch is preferred.

\section{Management}

B. orientalis often deposits oothecae in cracks and crevices that can be very difficult to treat with insecticides, or by the time the nymphs hatch from the oothecae the application is degraded or removed. Therefore new methods are being developed to manage the roach in combination with regular sprays and dusts. There has been an increased interest in recent years to use juvenile hormone analogues (JHAs) for the control of many insect pests. JHAs have a low vertebrate toxicity, a highly specific biological action and disrupt growth and reproduction in insects, which makes it a good candidate for use in domestic and public environments.

A chemical barrier around the perimeter of the home along with insecticides applied to specific locations inside will help control B. orientalis. However, rapid breakdown of the insecticides can 
occur because oriental cockroaches prefer to rest on damp surfaces. The following are some other tips that can help the management of $B$. orientalis in and around the home.

- The outsides of doors, windows, pipe openings and dryer vents should be treated with a good residual spray.

- Any plumbing leaks should be fixed, and any moist spaces should be ventilated.

- Cracks in the structure should be caulked at ground level.

- Decaying leaves and organic matter should be removed away from windows and doors.

- Garbage cans should be kept out of moist habitats

- Drain traps should be kept full or capped.

For further information please see, Insect Management Guide for Cockroaches.

\section{Selected References}

Edwards, J.P., and J.E. Short. Elimination of population of the Oriental cockroach

(Dictyoptera:Blattidae) in a simulated domestic environment with the insect hormone analogue (S)-Hydroprene. Journal of Economic Entomology. Vol. 86: pp. 436-443. 1993.

Koehler, P.G., D.E.Short and T.R. Fasulo. (1998). Pests In and Around the Home. UF/IFAS. SW-126. CD-ROM.

Thoms, E.M., and W.H. Robinson. Insecticide and structural modifications strategies for management of oriental cockroach (Orthoptera: Blattidae) populations. Journal of Economic Entomology. Vol. 80: pp131-135. 1987.

Thoms, E.M., and W.H. Robinson. Distribution, Seasonal Abundance, and Pest Status of the Oriental Cockroach (Orthoptera: Blattidae) and an Evaniid Wasp (Hymenoptera: Evaniidae) in Urban Apartments. Journal of Economic Entomology. Vol. 79: 431-436. 1986.
Thoms, E.M., and W.H. Robinson. Distribution and Movement of the Oriental Cockroach (Orthoptera: Blattidae) Around Apartment Buildings. Journal of Environmental Entomology. Vol. 16: 731-737. 1987.

Suiter, D.R. and P.G. Koehler. (October 1991). Oriental cockroach, Blattella orientalis. UF/IFAS. ENY-239. http://edis.ifas.ufl.edu/MG235 (22 June 2000). 